\title{
Clinical scores for outcomes of rhythm control or arrhythmia progression in patients with atrial fibrillation: a systematic review
}

\author{
Hai Deng ${ }^{1,2} \cdot$ Ying Bai $^{1,3}$ - Alena Shantsila ${ }^{1}$ Laurent Fauchier ${ }^{4}$ Tatjana S. Potpara ${ }^{5,6}$. \\ Gregory Y. H. Lip ${ }^{1,5,7}$
}

Received: 16 February 2017/ Accepted: 22 May 2017/Published online: 30 May 2017

(C) The Author(s) 2017. This article is an open access publication

\begin{abstract}
Patients with atrial fibrillation (AF) are commonly managed with rhythm control strategy, but the natural history of this common arrhythmia leads itself to progression from paroxysmal to persistent or permanent $\mathrm{AF}$, and recurrences are evident despite rhythm control treatments using cardioversion or catheter ablation. Numerous clinical factors have been associated with outcomes of rhythm control or arrhythmia progression in patients with AF. The more common factors have been used to formulate risk stratification scores, to help predict the outcomes of rhythm control treatments or AF progression. This review article provides an overview on the published clinical risk scores related to outcomes of rhythm control strategy or AF progression.
\end{abstract}

Keywords Atrial fibrillation - Rhythm control · Cardioversion $\cdot$ Catheter ablation

Gregory Y. H. Lip

g.y.h.lip@bham.ac.uk

1 Institute of Cardiovascular Sciences, University of Birmingham, City Hospital, Birmingham B18 7QH, UK

2 Guangdong Cardiovascular Institute, Guangdong General Hospital, Guangdong Academy of Medical Science, Guangzhou, China

3 Beijing Tongren Hospital, Capital University, Beijing, China

4 Service de Cardiologie, Centre Hospitalier Universitaire Trousseau, Tours, France

5 School of Medicine, Belgrade University, Belgrade, Serbia

6 Cardiology Clinic, Clinical Centre of Serbia, Belgrade, Serbia

7 Aalborg Thrombosis Research Unit, Department of Clinical Medicine, Aalborg University, Aalborg, Denmark

\section{Introduction}

Patients with atrial fibrillation (AF) are commonly managed with rhythm control strategy, but the natural history of this common arrhythmia leads itself to progression from paroxysmal to persistent or permanent $\mathrm{AF}$, and recurrences despite rhythm control treatments using cardioversion or catheter ablation (CA). The latter has been shown to have superior efficacy in the short- or long-term comparison with antiarrhythmic drugs (AAD) even in patients with persistent $\mathrm{AF}[1,2]$. As an interventional procedure, $\mathrm{CA}$ therapy still has various issues including arrhythmia recurrence, procedural complications, and high expenditure which are important considerations when physicians have to make decisions whether CA is appropriate or not. Ultimately, a decision of atrioventricular junction ablation with permanent ventricular pacing may also be considered rather than $\mathrm{AF}$ ablation in highly symptomatic patients with high risk of $\mathrm{AF}$ recurrences [3].

The recurrence rate of a single CA procedure ranges from 30 to 50\% [4]. Many clinical factors such as older age [5], non-paroxysmal AF [6], left atrial (LA) size [7], female sex [8], coronary artery disease (CAD) [4], hypertension (HTN) [9], diabetes mellitus (DM) [10], untreated obstructive sleep apnea (OSA) [4], metabolic syndrome (MetS) [11], body mass index (BMI) [12], chronic kidney disease (CKD) [13], heart failure (HF) [14, 15], early arrhythmia recurrence (ER) [16], and prior refractoriness to antiarrhythmic drugs [17] have been reported as predictor of recurrence after CA (see Table 1). Of the numerous clinical factors that have been associated with outcomes of rhythm control or arrhythmia progression in patients with $\mathrm{AF}$, those which are more common have been used to formulate risk stratification scores, to help predict outcomes of rhythm control or arrhythmia progression. 
Table 1 Examples of risk factors for AF recurrence after catheter ablation

\begin{tabular}{|c|c|c|c|}
\hline Risk factors & $\mathrm{CA}$ & CBA & References \\
\hline LAD & $\sqrt{ }$ & $\sqrt{ }$ & Zhuang [7], Chao [57], Miyazaki [58], Liu [59] \\
\hline LAD, PeAF, AF history & $\sqrt{ }$ & & Miao [60] \\
\hline Non-PAF & $\sqrt{ }$ & & Konrad [6], Chang [61] \\
\hline Epicardial adipose tissue thickness & $\sqrt{ }$ & & Chao [62], Kim [63] \\
\hline Early recurrence & $\sqrt{ }$ & $\sqrt{ }$ & Miyazaki [16], Evranos [64], Shim [65] \\
\hline Obstructive sleep apnea & $\sqrt{ }$ & & Naruse [66] \\
\hline Inflammatory factors & $\sqrt{ }$ & & Wu [67] \\
\hline Duration of $\mathrm{AF}$, gender & $\sqrt{ }$ & & Zhang [68] \\
\hline RA enlargement, $\geq 2$ procedure times, $\mathrm{AF}$ duration & $\sqrt{ }$ & & Zhao [69] \\
\hline Uric acid, LAD, early recurrence & & $\sqrt{ }$ & Canpolat [70] \\
\hline Low BMI, PeAF & $\sqrt{ }$ & & Fujino [71] \\
\hline PR interval & $\sqrt{ }$ & & Park [72] \\
\hline Duration of $\mathrm{AF}, \mathrm{LAD}$, number of ineffective $\mathrm{AAD}$ & $\sqrt{ }$ & & Takigawa [73] \\
\hline Age, LAD, BMI, valvular heart disease, PR interval & $\sqrt{ }$ & & $\mathrm{Wu}[74]$ \\
\hline TGF-beta1 & & $\sqrt{ }$ & Canpolat [75] \\
\hline Renal dysfunction & & $\sqrt{ }$ & Li, 2014 [13], Neumann [76] \\
\hline COPD & $\sqrt{ }$ & & $\mathrm{Gu}[77]$ \\
\hline Left ventricular systolic dysfunction & $\sqrt{ }$ & & Anselmino [14] \\
\hline Left ventricular diastolic dysfunction & $\sqrt{ }$ & & Kumar [15] \\
\hline Prior AAD failure, non-PAF, hypertension & $\sqrt{ }$ & & Khaykin [17] \\
\hline Hypertension & $\sqrt{ }$ & & Wang [9] \\
\hline Metabolic syndrome & $\sqrt{ }$ & & Lin [11] \\
\hline Diabetes mellitus & $\sqrt{ }$ & & Anselmino [10] \\
\hline Age & $\sqrt{ }$ & & The [5] \\
\hline Female & $\sqrt{ }$ & & Zylla, 2016 [8] \\
\hline
\end{tabular}

$A A D$ antiarrhythmic drug, $A F$, atrial fibrillation, $B M I$ body mass index, $C A$ catheter ablation, $C B A$ cryoballoon ablation, $C O P D$ chronic obstruct pulmonary disease, $L A D$ left atrial diameter, non- $P A F$ non-paroxysmal AF, $P e A F$ persistent $\mathrm{AF}$

Several such scores have been published, as summarized in Table 2.

The objective of this review article is to provide an overview on the published clinical risk scores related to outcomes of rhythm control strategy or arrhythmia progression.

\section{Search strategy}

Comprehensive literature search was performed using MEDLINE for studies reporting on the predictive scores of $\mathrm{AF}$ recurrence after $\mathrm{CA}$ or $\mathrm{AF}$ progression. Search terms included "atrial fibrillation", "ablation", "recurrence", "outcome", "progression", and "score". The articles retrieved by the search were selected by title and abstract screening. Nine relevant clinical scoring systems have been reported (Table 2). We summarized prediction, with c-indexes or area under the curve (AUC), or reclassification or discrimination indexes, where reported. As most clinical scores only had one associated paper related to rhythm control or arrhythmia progression, no meta-analysis was performed, given the heterogeneity of the patient populations studied.

\section{The HATCH score}

The HATCH scoring system was first developed to predict the clinical progression of paroxysmal to persistent $\mathrm{AF}$ [18]. In the original description, 1219 patients from the Euro Heart Survey on AF were included and were observed for more than 1 year. Different clinical variables were studied to evaluate the predictive value on AF progression, and heart failure $(\mathrm{H})$, older age $(\mathrm{A})$, previous transient ischemic attack (TIA) or stroke (T), chronic obstructive pulmonary disease (COPD,C), and hypertension $(\mathrm{H})$ were identified as independent predictors of AF progression.

Hypertension, age $\geq 75$ years, and COPD each were assigned 1 point, while TIA or stroke, and heart failure were scored 2 points, with the HATCH score ranging from 0 to 7 points. In the original study, nearly $50 \%$ of patients 
Table 2 Studies for predictive scores related to outcomes of rhythm control or arrhythmia progression in patients with atrial fibrillation

\begin{tabular}{|c|c|c|c|c|c|c|c|c|c|c|}
\hline $\begin{array}{l}\text { First } \\
\text { author, } \\
\text { year }\end{array}$ & $\begin{array}{l}\text { Scores } \\
\text { (points) }\end{array}$ & $\begin{array}{l}\text { Enrolled } \\
\text { patients } \\
\text { (n) }\end{array}$ & $\begin{array}{l}\mathrm{pAF} \\
(\%)\end{array}$ & CA protocol & $\begin{array}{l}\text { AFLAT- } \\
\text { Free }(\%)\end{array}$ & $\begin{array}{l}\text { Procedure } \\
\text { times }\end{array}$ & $\begin{array}{l}\text { FU } \\
\text { (months) }\end{array}$ & $\begin{array}{l}\text { C Index/ } \\
\text { AUC }\end{array}$ & $\begin{array}{l}\text { Predictive } \\
\text { value }\end{array}$ & $\begin{array}{l}\mathrm{CHADS}_{2} / \\
\mathrm{CHA}_{2} \mathrm{DS}_{2}- \\
\text { VASc } \\
\text { compared }\end{array}$ \\
\hline $\begin{array}{l}\text { Tang } \\
{[21],} \\
2012\end{array}$ & $\begin{array}{c}\text { HATCH } \\
(0-7)\end{array}$ & 488 & 100 & CPVI & 63.93 & Single & $27.4 \pm 17.7$ & $\begin{array}{l}\text { Not } \\
\text { measured }\end{array}$ & No & $\begin{array}{l}\text { Not } \\
\text { compared }\end{array}$ \\
\hline $\begin{array}{c}\text { Maciej } \\
\text { [23], } \\
2013\end{array}$ & $\begin{array}{l}\text { ALARMEc } \\
(0-5)\end{array}$ & 213 & 47 & Stepwise* & 90 & Repeated & 24 & $\begin{array}{c}0.657 \text { vs. } \\
0.533 / \\
0.519\end{array}$ & Yes & Worse \\
\hline $\begin{array}{l}\text { Ugur } \\
\text { [25] }\end{array}$ & $\begin{array}{l}\text { BASE-AF } \\
\quad(0-6)\end{array}$ & 236 & 79.6 & Cryoablation & 74.5 & Single & 20 & $\begin{array}{l}0.94 \text { (score } \\
\geq 3 \text { ) }\end{array}$ & Yes & $\begin{array}{l}\text { Not } \\
\text { compared }\end{array}$ \\
\hline $\begin{array}{c}\text { Letsas } \\
\text { [31] } \\
2014\end{array}$ & $\begin{array}{l}\mathrm{CHADS}_{2} \\
(0-6) / \\
\mathrm{CHA}_{2} \mathrm{DS}_{2}- \\
\text { VASc }(0-9)\end{array}$ & 126 & 100 & CPVI & 70.6 & Single & 16 & $\begin{array}{l}0.644 / \\
0.627 \\
(\text { score } \\
\geq 2 \text { ) }\end{array}$ & Yes & - \\
\hline $\begin{array}{c}\text { Kornej } \\
{[26],} \\
2015\end{array}$ & APPLE (0-5) & 261 & 48 & Stepwise* & 38.3 & Single & $\geq 12$ & $\begin{array}{c}0.634 \text { vs. } \\
0.538 / \\
0.542\end{array}$ & Yes & Worse \\
\hline $\begin{array}{r}\text { Roger } \\
\text { [28], } \\
2016\end{array}$ & $\begin{array}{l}\text { CAAP-AF } \\
(0-13)\end{array}$ & 937 & 31.6 & Stepwise* & 79.1 & Repeated & $21.6 \pm 1.6 a$ & 0.650 & Yes & $\begin{array}{l}\text { Not } \\
\text { compared }\end{array}$ \\
\hline $\begin{array}{c}\text { Mujovic } \\
\text { [29], } \\
2017\end{array}$ & $\begin{array}{l}\text { MB-LATER } \\
(0-6)\end{array}$ & 133 & 69.2 & Stepwise* & 85 & Repeated & $29 \pm 10.1$ & $\begin{array}{c}0.782 \text { vs. } \\
0.552 / \\
0.519\end{array}$ & Yes & Worse \\
\hline
\end{tabular}

$A F L A T$ atrial flutter or atrial tachycardia, $A U C$ area under curve, $C P V I$ circumferential pulmonary vein isolation, $F U$ follow-up, $p A F$ paroxysmal atrial fibrillation

* Stepwise, necessary additional linear lesion, or complex fractionated atrial electrogram-guided ablation after CPVI

with a HATCH score of $>5$ progressed to persistent AF, but only $6 \%$ of those with a score of 0 experienced $\mathrm{AF}$ progression. A subsequent study of AF patients who were awaiting CA found the HATCH score to be a poor predictor of AF progression [19]. Similar observations were seen in the Belgrade AF study, which showed that the HATCH score had only very modest predictive value (c statistic, 0.6) for the arrhythmia progression in a cohort of lone AF patients over a 12-year follow-up period [20].

Whether the HATCH score could be used to predict the outcome after CA of AF was studied by Tang et al. [21] in 488 patients with paroxysmal AF undergoing CA. After $27.4 \pm 17.7$-month follow-up, $69.93 \%$ of patients were free of late AF recurrence, but the HATCH score was not an independent predictor of recurrence on multivariable analysis. Thus, the HATCH could not reliably predict the outcome after CA.

The predictive value of the HATCH score was further explored recently. Suenari et al. [22] tested the score in a 670,804 patients' cohort to investigate its predictive value of new-onset AF. In this cohort, patients were 20 years older, than in derivation cohort, without $\mathrm{AF}$ history. During a follow-up of $9.0 \pm 2.2$ years, the AF incidence increased from 0.8 per 1000 patient-years for patients with a HATCH score of 0-57.3 per 1000 patient-years for those with 7. After adjustment for gender and comorbidities, the hazard ratio of each increment of the HATCH score in predicting new-onset AF was 2.059 (CI 2.027-2.093, $P<0.001$ ). The result showed that the HATCH score was useful in estimation and stratification of new-onset AF.

\section{The ALARMEc score}

The ALARMEc score [23] was first reported as a scoring system to predict the outcome of AF CA in a study comparing the ALARMEc score with the $\mathrm{CHADS}_{2}$ and $\mathrm{CHA}_{2} \mathrm{DS}_{2}-\mathrm{VASc}$ scores for stroke risk stratification. The ALARMEc score included five variables, as follows: AF type (A), Left Atrial size [normalized left atrial area (NLA) $\geq 10.25]$, Renal insufficiency (eGRF $<68 \mathrm{ml} / \mathrm{min}$ ), Metabolic syndrome and cardiomyopathy (c) with each variable scoring 1 point, and the score values ranging from 0 to 5 points. The ALARMEc score was tested in only 213 patients with paroxysmal AF or non-paroxysmal AF who underwent repeated CA. After a follow-up of up to 
60 months, only the ALARMEc score (AUC 0.657, $P<0.0001$ ) but not $\mathrm{CHADS}_{2}$ (AUC $0.533, P=0.413$ ) or $\mathrm{CHA}_{2} \mathrm{DS}_{2}-$ VASc (AUC $0.519, P=0.641$ ) score predicted outcomes after CA.

Another study [24] included 702 patients with AF and analyzed four of five risk factors in a modified (ARLAMEc) score. In this study, MetS and impaired renal function were independent predictors of $\mathrm{AF}$ postablation outcome, but NLA and AF type were non-predictive. For the outcome of repeated CA, MetS was not predictive for late recurrences, but impaired renal function remained a significant predictive factor. Result of this study had some difference from the previous one.

\section{BASE-AF2 score}

The BASE-AF2 score system [25] comprises six clinical variables, as follows: Body mass index (BMI) $>28 \mathrm{~kg} / \mathrm{m}^{2}$ (B), atrial dilatation $>40 \mathrm{~mm}$ (A), current smoking (S), early recurrence $(\mathrm{E})$, duration of $\mathrm{AF}>6$ years $(\mathrm{A})$, and nonparoxysmal AF type (F). Each variable scores 1 point, with the score range from 0 to 6 points.

This score was tested in a set of 236 patients with paroxysmal AF who underwent cryoablation, and those with AF recurrence had higher BASE-AF2 score values, with a score of $\geq 3$ points being an independent predictor of $\mathrm{AF}$ recurrence. This score was only tested in patients with AF undergoing cryoablation and its value in other CA modalities merits further study.

\section{The APPLE score}

The APPLE score [26] was derived from a cohort of AF patients from Germany and tested in a validation cohort from the US. This scoring system comprised of five variables, as follows: Age $>65$ years (A), persistent AF (P), impaired eGFR ( $<60 \mathrm{ml} / \mathrm{min} / 1.73 \mathrm{~m} 2)(\mathrm{P})$, LA diameter $\geq 43 \mathrm{~mm}$ (L), and $\mathrm{EF}<50 \%$ (E). Each variable scored 1 point with the score ranging from 0 to 5 points.

In the derivation cohort, logistic regression analyses showed that the APPLE, CHADS 2 , and $\mathrm{CHA}_{2} \mathrm{DS}_{2}-\mathrm{VASc}$ scores were significant predictors of $\mathrm{AF}$ recurrence between 3 and 12 months. Based on ROC curve analysis, the APPLE score had a better predictive value compared with $\mathrm{CHADS}_{2}$ and $\mathrm{CHA}_{2} \mathrm{DS}_{2}-\mathrm{VASc}$ score $(c$ index 0.634 vs. 0.538 and 0.542 , respectively, both $P<0.001$ ). Validation study [27] of the APPLE score also carried on a cohort $(n=379)$ under repeated CA. Compared with CHADS2 and $\mathrm{CHA}_{2} \mathrm{DS}_{2}-\mathrm{VASc}$ score, the APPLE score also had better predictive value of AF recurrence after repeated CA (AUC 0.617 vs. 0.577 and 0.590 , respectively, both $P<0.001)$. In the latest validation study, the risk (OR) of AF recurrence was 2.9, 3.0, and 6.0 for patients with APPLE score 1,2 , and $\geq 3$, respectively, when compared to an APPLE score of 0 (all $P<0.01$ ).

\section{The CAAP-AF score}

The CAAP-AF score [28] was initially described in a derivation cohort of $1125 \mathrm{AF}$ patients and tested in a validation cohort of $937 \mathrm{AF}$ patients who underwent first CA at the same centre. AF type included paroxysmal $\mathrm{AF}$ and non-paroxysmal AF. The score consisted of the following variables: CAD (C), LA diameter (A), age (A), persistent or long-standing $\mathrm{AF}(\mathrm{P})$, number of antiarrhythmic drugs failed $(\mathrm{A})$, and female sex $(\mathrm{F})$, which were independent risk factors of $\mathrm{AF}$ recurrence in the derivation cohort on multivariable analysis. Accordingly, the $\mathrm{C}, \mathrm{F}$, and $\mathrm{P}$ criteria were awarded 1,1 , and 2 points, respectively. The score was scored $0-4$ based on the different LA diameters of $<4.0,4.0$ to $<4.5,4.5$ to $<5.0,5.0$ to $<5.5$, and $\geq 5.5 \mathrm{~cm}$. The age criterion was given different points of $0-3$ for ages $<50,50$ to $<60,60$ to $<70$, and $\geq 70$ years. If patient had 1 or 2 antiarrhythmic drug failures, it scored 1 point. When the number was over 2 , it scored two points.

Thus, the CAAP-AF score system comprises six risk factors and the score ranges from 0 to 13 points. In the validation cohort, percentage of AF-free patients was identical to that seen in the derivation cohort (statistic $\mathrm{C}$ 0.650 vs. 0.691 ). Of note, the CAAP-AF score was based on a single centre experience and $\mathrm{AF}$ recurrence was detected only by $24 \mathrm{~h}$ or 7-day Holter but not by loop recorder implantation.

\section{The MB-LATER score}

The recently published MB-LATER score was recently proposed [29] to predict very late ( $>12$ months) recurrence of AF (VLRAF) after CA. In this score, five clinical factors are considered: male sex, bundle branch block, left atrial size $\geq 47 \mathrm{~mm}$, type of AF (paroxysmal, persistent, or longstanding persistent), and early recurrent AF. The MBLATER was derived from a small retrospective cohort and compared against other clinical scores (APPLE, ALARMEc, BASE-AF2, CHADS2, $\mathrm{CHA}_{2} \mathrm{DS}_{2}-\mathrm{VASc}$, or HATCH). When compared to these scores, the MBLATER demonstrated better predictive value (AUC 0.782 vs. $0.716,0.671,0.648,0.522,0.519$, or 0.583$)$ and improved identification of patients with subsequent VLRAF using decision curve analysis (DCA).

\section{The $\mathrm{CHADS}_{2}, \mathrm{CHA}_{2} \mathrm{DS}_{2}-\mathrm{VASc}$, and $\mathrm{R}_{2} \mathrm{CHADS}_{2}$ scores}

The $\mathrm{CHADS}_{2}$ (congestive heart failure, hypertension, Age $\geq 75$, diabetes mellitus, and stroke/transient ischemic 
attack), $\mathrm{CHA}_{2} \mathrm{DS}_{2}-\mathrm{VASc}$ (congestive heart failure, hypertension, age $\geq 75$ years, diabetes mellitus, stroke/transient ischemic attack, vascular disease, age 65-74 years, and female sex), and $\mathrm{R}_{2} \mathrm{CHADS}_{2}$ (renal dysfunction, congestive heart failure, hypertension, age $\geq 75$ years, diabetes mellitus, and stroke/transient ischemic attack) scores are risk scores for predicting stroke and thromboembolism [30]. Given that the risk factor components of these scores are common cardiovascular risk factors, it is no surprise that they can be [29] related to outcomes of rhythm control or arrhythmia progression.

For example, Letsas et al. reported that on univariate analysis, both $\mathrm{CHADS}_{2}$ and $\mathrm{CHA}_{2} \mathrm{DS}_{2}-\mathrm{VASc}$ scores were associated with $\mathrm{AF}$ recurrence in patients with paroxysmal AF undergoing a single $\mathrm{CA}$ procedure. A score of $\geq 2$ for both $\mathrm{CHADS}_{2}$ (AUC 0.644) and $\mathrm{CHA}_{2} \mathrm{DS}_{2}-\mathrm{VASc}$ (AUC 0.627 ) scores had the highest predictive value for $A F$ recurrence [31]. Another study [32], which included patients with paroxysmal $\mathrm{AF}$ and persistent $\mathrm{AF}$, reported that both $\mathrm{CHADS}_{2}(\mathrm{HR} 1.19, P<0.001)$ and $\mathrm{CHA}_{2} \mathrm{DS}_{2}-$ VASc (HR 1.15, $P<0.0001)$ scores were good in stratifying patients for 5-year outcomes after AF ablation, with the $\mathrm{CHA}_{2} \mathrm{DS}_{2}$-VASc (HR 1.13, $P=0.001$ ) score being superior to the $\mathrm{CHADS}_{2}$ score for predicting $\mathrm{AF}$ recurrence.

Kornej et al. [33] reported that AF type, LA diameter, and early recurrence (ER) were significant predictors of long-term recurrence post $\mathrm{AF}$ ablation, and not the $\mathrm{CHADS}_{2}, \mathrm{CHA}_{2} \mathrm{DS}_{2}-\mathrm{VASc}$, and $\mathrm{R}_{2} \mathrm{CHADS}_{2}$ scores. Reports on the predictive value of these stroke risk scores on rhythm control outcomes do not appear to have consistent results.

\section{A critique of the published scores}

AF recurrence after $\mathrm{CA}$ was defined as AF/AT/AFL episode lasting $30 \mathrm{~s}$ with or without symptom recorded over 3 months after the procedure in the derivation or validation research of all the clinical scores.

Scoring systems described above used different predictive clinical factors in combination (see Table 3). Some of these factors like BMI and MetS had conflict results $[11,12]$. One meta-analysis found that recurrence within 30 days, LA diameter of $>50 \mathrm{~mm}$, and valvular AF were the most powerful predictors of CA failure [34].

From the clinical perspective, AF progression could be defined as development of persistent or long-standing AF in patients with paroxysmal AF. In the derivation study of HATCH score, five clinical factors were identified as independent predictors of AF progression (see Table 3). Although these factors have previously been reported separately (see Table 1), the intrinsic mechanistic link and the development of the substrate for AF or its progression

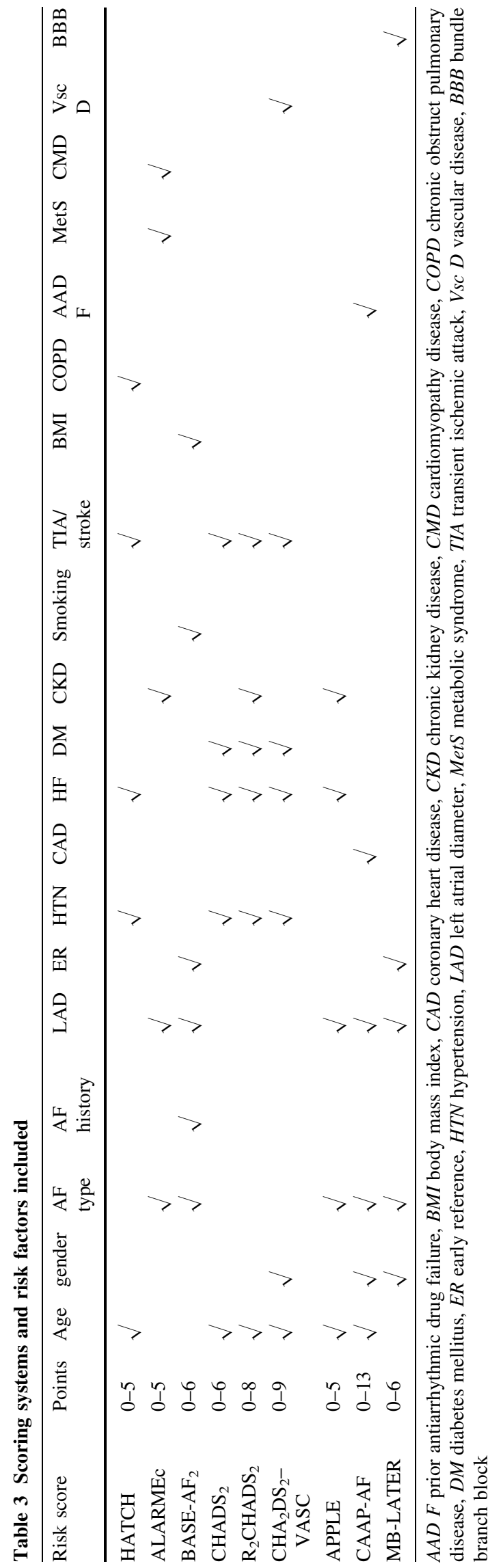


requires further study. The predictive value in $\mathrm{AF}$ progression of the HATCH score is still controversial, but result of recent validation study on new-onset AF demonstrated good predictive ability. Clinical applicability of the HATCH score needs much more evidence to support.

Five scores derived from different cohorts, that is, the ALARMEc, BASE-AF2, APPLE, CAAP-AF, and MBLATER, included the LA size as one of the predictive variables. Nonetheless, the size of LA was differently defined in different scores. For example, LA size was defined as $>43 \mathrm{~mm}$ in APPLE score, $>40 \mathrm{~mm}$ in BASEAF2 score, $>47 \mathrm{~mm}$ in MB-LATER, and $>50 \mathrm{~mm}$ in ALARMEc score, and stratified into five categories of $<40$, 40 to $<45,45$ to $<50,50$ to $<55$, and $\geq 55 \mathrm{~mm}$ in the CAAP-AF score. Given that they were not initially developed to predict the rhythm outcome following CA, the $\mathrm{CHADS}_{2}, \mathrm{CHA}_{2} \mathrm{DS}_{2}-\mathrm{VASc}, \mathrm{R}_{2} \mathrm{CHADS}_{2}$, and HATCH scores did not include LA size as one of their component risk factors.

LA enlargement is involved in mechanism of AF formation and progression. Atrial fibrosis may be an important feature for AF perpetuation, and it may be evaluated using cardiac imaging [35] or biomarkers [36-38]. Interestingly, fibrosis may be found in AF patients with no LA enlargement. Whether these parameters may improve the predictive value of scores aiming to identify the risk of arrhythmia progression should be evaluated in the future. Some of the included risk factors could relate to pathophysiological changes in the LA. For example, patients with HTN were found to have increasing size of scar and low-voltage area in the LA when mapping during the CA procedure [9]. MetS may play an important role in the atrial electrical activity by promoting the atrial conduction disturbances and dispersion of refractoriness between the right and left atrium [39]. In addition, obesity [40] is associated with a shortened effective refractory period in the pulmonary veins.

AF subtype was another variable included in five scoring systems (see Table 3). Electrical changes promoting arrhythmia perpetuation are induced by the presence of $\mathrm{AF}$ itself, which has also been called "AF begets AF" several years ago. From the onset of AF, the LA undergoes gradual electrical and structural remodeling which ultimately forms a substrate capable to maintain AF. Non-paroxysmal AF has been associated with lower AF termination rates and worse outcome after CA compared to paroxysmal AF [6]. The predictive value of $\mathrm{AF}$ duration for postablation recurrence of non-paroxysmal AF has been reported widely $[6,17,41]$.

Early AF recurrence was only included in the BASEAF2 and MB-LATER score. As we know, early recurrence is observed only after CA, and while of limited use in preablation decision, it might be useful to predict rhythm outcome following repeated ablation procedures, as a reconnection of the PV-LA electrical conduction is considered to be the main mechanism of ER [16] as well as recurrence [42]. Thus, LA size, AF type, and ER, which may directly contribute to the AF substrate, should be considered as most important parameters included within the five main scoring systems.

Other risk factors were shared in several scores. Age was risk factor of the HATCH, CHADS $2, \mathrm{R}_{2} \mathrm{CHA}_{2} \mathrm{DS}_{2}$, $\mathrm{CHA}_{2} \mathrm{DS}_{2}-\mathrm{VASc}$, APPLE, and CAAP-AF scores. Heart failure (HF) was shared in the HATCH, CHADS $2, \mathrm{R}_{2}$ $\mathrm{CHA}_{2} \mathrm{DS}_{2}, \mathrm{CHA}_{2} \mathrm{DS}_{2}-\mathrm{VASc}$, and CAAP-AF score. These two factors were previously reported elsewhere. Incidence of $\mathrm{HF}$ is increased in $\mathrm{AF}$ patients which encourage a rhythm control strategy [43]. Vice versa, patients with HF progress to AF more easier than those without and evidence showed that risk profile is shared by HF and AF [44].

Of the five mentioned scores, the ALARMEc, BASE$\mathrm{AF}_{2}$, APPLE, CAAP-AF, and MB-LATER scores each were tested in only one study, and these studies included patients with different AF types. Only the $\mathrm{BASE}-\mathrm{AF}_{2}$ score used the cryoablation technique which could have had some influence on the outcome of non-paroxysmal AF patients. Indeed, cryoablation just performs a circumferential pulmonary vein isolation (CPVI) and the result in non-paroxysmal AF ablation may potentially be suboptimal with cryoablation [25], although the optimal strategy for ablation in non-paroxysmal AF still needs to be established [45]. Compared to the MB-LATER score, the BASE-AF2 score also had moderate predictive value (AUC 0.648) for VLRAF [25].

The other four studies used radio frequency $\mathrm{CA}$ and a stepwise protocol, especially with non-paroxysmal AF, where patients would sometime need to have linear lesions (LL), mitral/tricuspid isthmus ablation, superior vena cava isolation, or complex fractionated atrial electrogram ablation (CFAE) when AF is continuous after the CPVI $[23,26,28]$. There were minor differences among the approaches used in these four studies. Patients from the CAAP-AF cohort underwent CPVI and roof linear lesions in both paroxysmal or non-paroxysmal AF, and coronary sinus ablation was performed. In the derivation cohort of the APPLE score, electrical cardioversion was used initially if AF presented at the beginning of the CA procedure. However, in the validation cohort, cardioversion was used when $\mathrm{AF}$ was continuous after CPVI, roof linear lesion, mitral linear lesion, base posterior wall lesion, or CFAE, although the efficacy of additional linear lesion and CFAE on sinus rhythm maintaining after CA has not been firmly established [46, 47]. None of these studies provided much detail on ablation parameters, complication, and AF termination of the procedure, which might influence the acute procedural rate of AF. As far as we known, new techniques 
are evolving within CA such as contact force catheter [48] and second-generation cryoballoon [49], new mapping systems (e.g., focal impulse and rotor or high dominant frequency mapping) [50,51], and new ablation technique (e.g., hybrid or epicardial ablation) [52] have influenced the efficiency and safety of AF ablation. Hence, the predictive value of these clinical scores would need to be validated in cohorts undergoing ablation with newer ablation catheters or techniques.

The follow-up period of five derivation studies has some differences (see Table 2). Patients in these studies were followed up at least 12 months. Arrhythmia symptom with 12-lead ECG evidence and continuous Holter ECG monitor were used to detect AF recurrence. Patients accepted 7-day Holter for every 3 months in studies on the ALARMEc and APPLE scores, and then once a year in the study on the ALARMEc score. Of the validation cohort of the CAAPAF score, patients accepted 24-48 h Holter every 3-12 months but switched to 7-14-days Holter after 2006. Patients of the BASE-AF2 cohort were only accepted with $24 \mathrm{~h}$ Holter every 3 months. In the MB-LATER cohort, patients underwent 12-lead ECG and $24 \mathrm{~h}$ Holter at discharge, 1, 3, and 6 months after procedure, and then every 6 months thereafter. If patients complained with symptoms suggestive of arrhythmia recurrence, more extensive arrhythmia monitoring would be performed. Asymptomatic AF sometimes occurred much more frequently than symptomatic AF [53]. None of these studies use implanted recorder to detect the arrhythmia recurrence which makes their estimation of $\mathrm{AF}$ recurrent rate suboptimal. For expense or non-invasive reason, wearable instrument which was usually used to avoid unnecessary ICD implantation might take as the substitution [54]. Testing studies on these scores with much precise recurrent $\mathrm{AF}$ rate may help to improve overcome this limitation. Some evidence has shown that the two ablation techniques with cryoablation and radiofrequency had similar efficacy [49] in patients with paroxysmal $\mathrm{AF}$, but evidence in persistent $\mathrm{AF}$ is scarce.

The $\mathrm{CHADS}_{2}, \mathrm{CHA}_{2} \mathrm{DS}_{2}-\mathrm{VASc}$, and $\mathrm{R}_{2} \mathrm{CHADS}_{2}$ scores, which are not rhythm-related risk scores, were tested in different cohorts with conflicting results. The HATCH score had no significant value on predicting the recurrence after CA [21]. Three clinical scores determined before the $\mathrm{CA}$ procedure could be used to predict $\mathrm{AF}$ recurrence post CA. In the studies describing the ALARMEc and CAAP-AF scores [23, 28], the scores' predictive value for repeated CA outcome was also evaluated. Validation tests of the ALARMEc score were contradictory and the CAAP-AF score was not validated by any other cohort. For now, the APPLE score has been validated in at least three cohorts (AUC 0.634, 0.617, and 0.716, all $P<0.05$ ) including the derivation cohort of MB-LATER score. Risk factors of the APPLE score are easily acquired clinical indices, which makes this score a good predictor of $\mathrm{AF}$ recurrence post CA.

For early recurrence based on clinical factors after the CA procedure, the BASE-AF2 and MB-LATER scores $[25,29]$ could be used to predict $A F$ recurrence post $C A$. The predictive value of BASE-AF2 is perhaps more limited given the derivation study design. The MB-LATER score was newly derived and validated for the predictive value of VLAFR and compared to the other six scores except for the CAAP-AF score. The MB-LATER score was shown to have better predictive value for VLAFR than other scores in a small prospective cohort $(n=133)$ study. Although there is only one report for now, the MB-LATER score appeared to be a good tool to predict VLAFR, but the value for $\mathrm{AF}$ recurrence after $\mathrm{CA}$ needs to be further validated. In the validation studies of the APPLE and the MB-LATER score, different points or cut-off analyses were carried out. Overall, the predictive value of all these scores still requires more validation studies to help decision-making on $\mathrm{AF}$ recurrence ablation or postablation outcomes.

\section{Limitations}

The majority of the derivation studies used to develop these scoring systems had observational retrospective designs and some scores lacked external validation cohorts. In addition, patients who undergo cryoablation usually have less risk factors. Based on our review, all scores were derived from different cohorts, which made components of them rather different. Our purpose was to report every clinical score that had been derived and try to compare their reported clinical predictive value(s) in relation to CA method(s). While we fully recognize that cryoablation is one type of ablation method/technology, but a recent report from the Fire and Ice trial [ref] showed it had similar outcomes to PAF patients undergoing RF ablation. Persistent AF may need additional ablation approaches, such as linear lesion (LL), but meta-analysis does not suggest that LL following pulmonary vein isolation (PVI) provides additional benefit for sinus rhythm maintenance. Given the possible heterogeneity of reported cohorts and also that our focus was not on ablation technique, our review does not focus on outcomes in relation to comparison of ablation methods. Finally, the predictive value of the scores on AF progression and recurrence requires to be confirmed in future studies. Large cohorts should be used to test all these scores to confirm their clinical applicability. Case studies from different centres often not large, multicentre clinical trial data or different centre combining the data might be of help like the derivation of the TIMI-AF score [55] and the AF-CVS score [56]. Until large prospective cohorts exist, we should regard application of these scores as hypothesis 
generating, but using these scores may provide some insights on who may (or may not) do well following ablation.

\section{Conclusion}

Several predictive scores for rhythm outcome of $\mathrm{AF}$ recurrence postCA have been developed and tested, but evidence of their predictive value still requires further evaluation. Many risk factor components of these scores have been reported as independent predictors of CA outcome, whether directly or indirectly contributing to $\mathrm{AF}$ substrate formation. For now, the risk scores for recurrences following CA have limited validation.

\section{Compliance with ethical standards}

Funding None. This work was conducted independent of any industry collaboration or sponsorship.

Conflict of interest GYHL has served as a consultant for Bayer/ Janssen, BMS/Pfizer, Biotronik, Medtronic, Boehringer Ingelheim, Microlife, and Daiichi-Sankyo, and as a speaker for Bayer, BMS/ Pfizer, Medtronic, Boehringer Ingelheim, Microlife, Roche, and Daiichi-Sankyo. Other authors: none declared.

Open Access This article is distributed under the terms of the Creative Commons Attribution 4.0 International License (http://crea tivecommons.org/licenses/by/4.0/), which permits unrestricted use, distribution, and reproduction in any medium, provided you give appropriate credit to the original author(s) and the source, provide a link to the Creative Commons license, and indicate if changes were made.

\section{References}

1. Cheng X, Li X, He Y, Liu X, Wang G, Cheng L, Hu J (2014) Catheter ablation versus anti-arrhythmic drug therapy for the management of a trial fibrillation: a meta-analysis. J Interv Card Electrophysiol Int J Arrhythm Pacing 41(3):267-272. doi:10. 1007/s10840-014-9945-4

2. Wynn GJ, Das M, Bonnett LJ, Panikker S, Wong T, Gupta D (2014) Efficacy of catheter ablation for persistent atrial fibrillation: a systematic review and meta-analysis of evidence from randomized and nonrandomized controlled trials. Circ Arrhythm Electrophysiol 7(5):841-852. doi:10.1161/CIRCEP.114.001759

3. Garcia B, Clementy N, Benhenda N, Pierre B, Babuty D, Olshansky B, Fauchier L (2016) Mortality after atrioventricular nodal radiofrequency catheter ablation with permanent ventricular pacing in atrial fibrillation: outcomes from a controlled nonrandomized study. Circ Arrhythm Electrophysiol. doi:10.1161/ CIRCEP.116.003993

4. Kirchhof P, Benussi S, Kotecha D, Ahlsson A, Atar D, Casadei B, Castella M, Diener HC, Heidbuchel H, Hendriks J, Hindricks G, Manolis AS, Oldgren J, Popescu BA, Schotten U, Van Putte B, Vardas P, Agewall S, Camm J, Baron Esquivias G, Budts W, Carerj S, Casselman F, Coca A, De Caterina R, Deftereos S, Dobrev D, Ferro JM, Filippatos G, Fitzsimons D, Gorenek B,
Guenoun M, Hohnloser SH, Kolh P, Lip GY, Manolis A, McMurray J, Ponikowski P, Rosenhek R, Ruschitzka F, Savelieva I, Sharma S, Suwalski P, Tamargo JL, Taylor CJ, Van Gelder IC, Voors AA, Windecker S, Zamorano JL, Zeppenfeld K (2016) 2016 ESC Guidelines for the management of atrial fibrillation developed in collaboration with EACTS. Eur Eur Pacing Arrhythm Card Electrophysiol J Working Groups Card Pacing Arrhythm Card Cell Electrophysiol Eur Soc Cardiol 18(11):1609-1678. doi:10.1093/europace/euw295

5. Teh AW, Kalman JM, Lee G, Medi C, Heck PM, Ling LH, Kumar S, Spence SJ, Morton JB, Kistler PM (2012) Electroanatomic remodelling of the pulmonary veins associated with age. Eur Eur Pacing Arrhythm Card Electrophysiol J Working Groups Card Pacing Arrhythm Card Cell Electrophysiol Eur Soc Cardiol 14(1):46-51. doi:10.1093/europace/eur275

6. Konrad T, Theis C, Mollnau H, Sonnenschein S, Ocete BQ, Bock K, Munzel T, Rostock T (2015) Primary persistent atrial fibrillation: a distinct arrhythmia subentity of an ablation population. J Cardiovasc Electrophysiol 26(12):1289-1294. doi:10.1111/jce. 12818

7. Zhuang J, Wang Y, Tang K, Li X, Peng W, Liang C, Xu Y (2012) Association between left atrial size and atrial fibrillation recurrence after single circumferential pulmonary vein isolation: a systematic review and meta-analysis of observational studies. Eur Eur Pacing Arrhythm Card Electrophysiol J Working Groups Card Pacing Arrhythm Card Cell Electrophysiol Eur Soc Cardiol 14(5):638-645. doi:10.1093/europace/eur364

8. Zylla MM, Brachmann J, Lewalter T, Hoffmann E, Kuck KH, Andresen D, Willems S, Eckardt L, Tebbenjohanns J, Spitzer SG, Schumacher B, Hochadel M, Senges J, Katus HA, Thomas D (2016) Sex-related outcome of atrial fibrillation ablation: insights from the German Ablation Registry. Heart Rhythm Off J Heart Rhythm Soc 13(9):1837-1844. doi:10.1016/j.hrthm.2016.06.005

9. Wang T, Xia YL, Zhang SL, Gao LJ, Xie ZZ, Yang YZ, Zhao J (2014) The impact of hypertension on the electromechanical properties and outcome of catheter ablation in atrial fibrillation patients. J Thorac Dise 6(7):913-920. doi:10.3978/j.issn.20721439.2014.06.31

10. Anselmino M, Matta M, D’Ascenzo F, Pappone C, Santinelli V, Bunch TJ, Neumann T, Schilling RJ, Hunter RJ, Noelker G, Fiala M, Frontera A, Thomas G, Katritsis D, Jais P, Weerasooriya R, Kalman JM, Gaita F (2015) Catheter ablation of atrial fibrillation in patients with diabetes mellitus: a systematic review and metaanalysis. Eur Eur Pacing Arrhythm Card Electrophysiol J Working Groups Card Pacing Arrhythm Card Cell Electrophysiol Eur Soc Cardiol 17(10):1518-1525. doi:10.1093/europace/ euv214

11. Lin KJ, Cho SI, Tiwari N, Bergman M, Kizer JR, Palma EC, Taub CC (2014) Impact of metabolic syndrome on the risk of atrial fibrillation recurrence after catheter ablation: systematic review and meta-analysis. J Interv Card Electrophysiol Int J Arrhythm Pacing 39(3):211-223. doi:10.1007/s10840-013-9863$\mathrm{x}$

12. Zhuang J, Lu Y, Tang K, Peng W, Xu Y (2013) Influence of body mass index on recurrence and quality of life in atrial fibrillation patients after catheter ablation: a meta-analysis and systematic review. Clin Cardiol 36(5):269-275. doi:10.1002/clc.22108

13. Li M, Liu T, Luo D, Li G (2014) Systematic review and metaanalysis of chronic kidney disease as predictor of atrial fibrillation recurrence following catheter ablation. Cardiol $\mathrm{J}$ 21(1):89-95. doi:10.5603/CJ.a2013.0116

14. Anselmino M, Matta M, D'Ascenzo F, Bunch TJ, Schilling RJ, Hunter RJ, Pappone C, Neumann T, Noelker G, Fiala M, Bertaglia E, Frontera A, Duncan E, Nalliah C, Jais P, Weerasooriya R, Kalman JM, Gaita F (2014) Catheter ablation of atrial fibrillation in patients with left ventricular systolic dysfunction: a 
systematic review and meta-analysis. Circ Arrhythm Electrophysiol 7(6):1011-1018. doi:10.1161/CIRCEP.114.001938

15. Kumar P, Patel A, Mounsey JP, Chung EH, Schwartz JD, Pursell IW, Gehi AK (2014) Effect of left ventricular diastolic dysfunction on outcomes of atrial fibrillation ablation. Am J Cardiol 114(3):407-411. doi:10.1016/j.amjcard.2014.05.012

16. Miyazaki S, Taniguchi H, Nakamura H, Takagi T, Iwasawa J, Hachiya H, Iesaka Y (2015) Clinical significance of early recurrence after pulmonary vein antrum isolation in paroxysmal atrial fibrillation-insight into the mechanism. Circ J Off J Jpn Circ Soc 79(11):2353-2359. doi:10.1253/circj.CJ-15-0475

17. Khaykin Y, Oosthuizen R, Zarnett L, Essebag V, Parkash R, Seabrook C, Beardsall M, Tsang B, Wulffhart Z, Verma A (2011) Clinical predictors of arrhythmia recurrences following pulmonary vein antrum isolation for atrial fibrillation: predicting arrhythmia recurrence post-PVAI. J Cardiovasc Electrophysiol 22(11):1206-1214. doi:10.1111/j.1540-8167.2011.02108.x

18. de Vos CB, Pisters R, Nieuwlaat R, Prins MH, Tieleman RG, Coelen RJ, van den Heijkant AC, Allessie MA, Crijns HJ (2010) Progression from paroxysmal to persistent atrial fibrillation clinical correlates and prognosis. J Am Coll Cardiol 55(8):725-731. doi:10.1016/j.jacc.2009.11.040

19. Kochhauser S, Dechering DG, Trought K, Hache P, Haig-Carter T, Khaykin Y, Wulffhart Z, Pantano A, Tsang B, Eckardt L, Verma A (2016) Predictors for progression of atrial fibrillation in patients awaiting atrial fibrillation ablation. Can $\mathrm{J}$ Cardiol 32(11):1348-1354. doi:10.1016/j.cjca.2016.02.031

20. Potpara TS, Stankovic GR, Beleslin BD, Polovina MM, Marinkovic JM, Ostojic MC, Lip GY (2012) A 12-year follow-up study of patients with newly diagnosed lone atrial fibrillation: implications of arrhythmia progression on prognosis: the Belgrade Atrial Fibrillation study. Chest 141(2):339-347. doi:10. 1378/chest.11-0340

21. Tang RB, Dong JZ, Long DY, Yu RH, Ning M, Jiang CX, Sang CH, Liu XH, Ma CS (2012) Efficacy of catheter ablation of atrial fibrillation beyond HATCH score. Chin Med J 125(19):3425-3429

22. Suenari K, Chao TF, Liu CJ, Kihara Y, Chen TJ, Chen SA (2017) Usefulness of HATCH score in the prediction of new-onset atrial fibrillation for Asians. Medicine 96(1):e5597. doi:10.1097/MD. 0000000000005597

23. Wojcik M, Berkowitsch A, Greiss H, Zaltsberg S, Pajitnev D, Deubner N, Hamm CW, Pitschner HF, Kuniss M, Neumann T (2013) Repeated catheter ablation of atrial fibrillation: how to predict outcome? Circ J Off J Jpn Circ Soc 77(9):2271-2279

24. Berkowitsch A, Kuniss M, Greiss H, Wojcik M, Zaltsberg S, Lehinant S, Erkapic D, Pajitnev D, Pitschner HF, Hamm CW, Neumann $T$ (2012) Impact of impaired renal function and metabolic syndrome on the recurrence of atrial fibrillation after catheter ablation: a long term follow-up. Pacing Clin Electrophysiol PACE 35(5):532-543. doi:10.1111/j.1540-8159.2012. 03350.x

25. Canpolat U, Aytemir K, Yorgun H, Sahiner L, Kaya EB, Oto A (2013) A proposal for a new scoring system in the prediction of catheter ablation outcomes: promising results from the Turkish Cryoablation Registry. Int J Cardiol 169(3):201-206. doi:10. 1016/j.ijcard.2013.08.097

26. Kornej J, Hindricks G, Shoemaker MB, Husser D, Arya A, Sommer P, Rolf S, Saavedra P, Kanagasundram A, Patrick Whalen S, Montgomery J, Ellis CR, Darbar D, Bollmann A (2015) The APPLE score: a novel and simple score for the prediction of rhythm outcomes after catheter ablation of atrial fibrillation. Clin Res Cardiol Off J German Card Soc 104(10):871-876. doi:10.1007/s00392-015-0856-x

27. Kornej J, Hindricks G, Arya A, Sommer P, Husser D, Bollmann A (2017) The APPLE score: a novel score for the prediction of rhythm outcomes after repeat catheter ablation of atrial fibrillation. PLoS One 12(1):e0169933. doi:10.1371/journal.pone. 0169933

28. Winkle RA, Jarman JW, Mead RH, Engel G, Kong MH, Fleming W, Patrawala RA (2016) Predicting atrial fibrillation ablation outcome: the CAAP-AF score. Heart Rhythm Off J Heart Rhythm Soc 13(11):2119-2125. doi:10.1016/j.hrthm.2016.07.018

29. Mujovic N, Marinkovic M, Markovic N, Shantsila A, Lip GY, Potpara TS (2017) Prediction of very late arrhythmia recurrence after radiofrequency catheter ablation of atrial fibrillation: the MB-LATER clinical score. Sci Rep 7:40828. doi:10.1038/ srep40828

30. Kornej J, Hindricks G, Kosiuk J, Arya A, Sommer P, Husser D, Rolf S, Richter S, Piorkowski C, Gaspar T, Lip GY, Bollmann A (2013) Renal dysfunction, stroke risk scores (CHADS2, CHA2DS2-VASc, and R2CHADS2), and the risk of thromboembolic events after catheter ablation of atrial fibrillation: the Leipzig Heart Center AF Ablation Registry. Circ Arrhythm Electrophysiol 6(5):868-874. doi:10.1161/CIRCEP.113.000869

31. Letsas KP, Efremidis M, Giannopoulos G, Deftereos S, Lioni L, Korantzopoulos P, Vlachos K, Xydonas S, Kossyvakis C, Sideris A (2014) CHADS2 and $\mathrm{CHA}_{2} \mathrm{DS}_{2}$-VASc scores as predictors of left atrial ablation outcomes for paroxysmal atrial fibrillation. Eur Eur Pacing Arrhythm Card Electrophysiol J Working Groups Card Pacing Arrhythm Card Cell Electrophysiol Eur Soc Cardiol 16(2):202-207. doi:10.1093/europace/eut210

32. Jacobs V, May HT, Bair TL, Crandall BG, Cutler M, Day JD, Weiss JP, Osborn JS, Muhlestein JB, Anderson JL, Mallender C, Bunch TJ (2015) The impact of risk score (CHADS2 versus $\mathrm{CHA}_{2} \mathrm{DS}_{2}$-VASc) on long-term outcomes after atrial fibrillation ablation. Heart Rhythm Off J Heart Rhythm Soc 12(4):681-686. doi:10.1016/j.hrthm.2014.12.034

33. Kornej J, Hindricks G, Kosiuk J, Arya A, Sommer P, Husser D, Rolf S, Richter S, Huo Y, Piorkowski C, Bollmann A (2014) Comparison of CHADS2, R2CHADS2, and $\mathrm{CHA}_{2} \mathrm{DS}_{2}$-VASc scores for the prediction of rhythm outcomes after catheter ablation of atrial fibrillation: the Leipzig Heart Center AF Ablation Registry. Circ Arrhythm Electrophysiol 7(2):281-287. doi:10.1161/CIRCEP.113.001182

34. D'Ascenzo F, Corleto A, Biondi-Zoccai G, Anselmino M, Ferraris F, di Biase L, Natale A, Hunter RJ, Schilling RJ, Miyazaki S, Tada H, Aonuma K, Yenn-Jiang L, Tao H, Ma C, Packer D, Hammill S, Gaita F (2013) Which are the most reliable predictors of recurrence of atrial fibrillation after transcatheter ablation?: a meta-analysis. Int J Cardiol 167(5):1984-1989. doi:10.1016/j. ijcard.2012.05.008

35. Gal P, Marrouche NF (2015) Magnetic resonance imaging of atrial fibrosis: redefining atrial fibrillation to a syndrome. Eur Heart J. doi:10.1093/eurheartj/ehv514

36. Takemoto Y, Ramirez RJ, Yokokawa M, Kaur K, Ponce-Balbuena D, Sinno MC, Willis BC, Ghanbari H, Ennis SR, GuerreroSerna G, Henzi BC, Latchamsetty R, Ramos-Mondragon R, Musa H, Martins RP, Pandit SV, Noujaim SF, Crawford T, Jongnarangsin K, Pelosi F, Bogun F, Chugh A, Berenfeld O, Morady F, Oral H, Jalife J (2016) Galectin-3 regulates atrial fibrillation remodeling and predicts catheter ablation outcomes. JACC Basic Transl Sci 1(3):143-154. doi:10.1016/j.jacbts.2016.03.003

37. Clementy N, Benhenda N, Piver E, Pierre B, Bernard A, Fauchier L, Pages JC, Babuty D (2016) Serum Galectin-3 levels predict recurrences after ablation of atrial fibrillation. Sci Rep 6:34357. doi:10.1038/srep34357

38. Kottkamp H, Bender R, Berg J (2015) Catheter ablation of atrial fibrillation: how to modify the substrate? J Am Coll Cardiol 65(2):196-206. doi:10.1016/j.jacc.2014.10.034

39. Tanaka K, Zlochiver S, Vikstrom KL, Yamazaki M, Moreno J, Klos M, Zaitsev AV, Vaidyanathan R, Auerbach DS, Landas S, 
Guiraudon G, Jalife J, Berenfeld O, Kalifa J (2007) Spatial distribution of fibrosis governs fibrillation wave dynamics in the posterior left atrium during heart failure. Circ Res 101(8):839-847. doi:10.1161/CIRCRESAHA.107.153858

40. Munger TM, Dong YX, Masaki M, Oh JK, Mankad SV, Borlaug BA, Asirvatham SJ, Shen WK, Lee HC, Bielinski SJ, Hodge DO, Herges RM, Buescher TL, Wu JH, Ma C, Zhang Y, Chen PS, Packer DL, Cha YM (2012) Electrophysiological and hemodynamic characteristics associated with obesity in patients with atrial fibrillation. J Am Coll Cardiol 60(9):851-860. doi:10.1016/ j.jacc.2012.03.042

41. Lodzinski P, Kiliszek M, Kozluk E, Piatkowska A, Balsam P, Kochanowski J, Scislo P, Piatkowski R, Opolski G (2014) Does a blanking period after pulmonary vein isolation impact long-term results? Results after 55 months of follow-up. Cardiol J 21(4):384-391. doi:10.5603/CJ.a2013.0144

42. Wasmer K, Dechering DG, Kobe J, Monnig G, Pott C, Frommeyer G, Lange PS, Kochhauser S, Eckardt L (2016) Pulmonary vein reconnection and arrhythmia progression after antral linear catheter ablation of paroxysmal and persistent atrial fibrillation. Clin Res Cardiol Off J German Card Soc 105(9):738-743. doi:10. 1007/s00392-016-0980-2

43. Pandey A, Kim S, Moore C, Thomas L, Gersh B, Allen LA, Kowey PR, Mahaffey KW, Hylek E, Peterson ED, Piccini JP, Fonarow GC (2017) Predictors and prognostic implications of incident heart failure in patients with prevalent atrial fibrillation. JACC Heart failure 5(1):44-52. doi:10.1016/j.jchf.2016.09.016

44. Singh JP, Thomas SS (2017) Atrial fibrillation and heart failure prevention: do we need a risk score? JACC Heart Fail 5(1):53-55. doi:10.1016/j.jchf.2016.11.005

45. Kirchhof P, Calkins H (2016) Catheter ablation in patients with persistent atrial fibrillation. Eur Heart J. doi:10.1093/eurheartj/ ehw260

46. Wong KC, Paisey JR, Sopher M, Balasubramaniam R, Jones M, Qureshi N, Hayes CR, Ginks MR, Rajappan K, Bashir Y, Betts TR (2015) No benefit of complex fractionated atrial electrogram ablation in addition to circumferential pulmonary vein ablation and linear ablation: benefit of complex ablation study. Circ Arrhythm Electrophysiol 8(6):1316-1324. doi:10.1161/CIRCEP. 114.002504

47. Zhang Z, Letsas KP, Zhang N, Efremidis M, Xu G, Li G, Liu T (2016) Linear ablation following pulmonary vein isolation in patients with atrial fibrillation: a meta-analysis. Pacing Clin Electrophysiol PACE 39(6):623-630. doi:10.1111/pace.12841

48. Pambrun T, Combes S, Sousa P, Bloa ML, El Bouazzaoui R, Grand-Larrieu D, Thompson N, Martin R, Combes N, Boveda S, Haissaguerre M, Albenque JP (2016) Contact-force guided single-catheter approach for pulmonary vein isolation: feasibility, outcomes, and cost-effectiveness. Heart Rhythm Off J Heart Rhythm Soc. doi:10.1016/j.hrthm.2016.12.008

49. Kuck KH, Brugada J, Furnkranz A, Metzner A, Ouyang F, Chun KR, Elvan A, Arentz T, Bestehorn K, Pocock SJ, Albenque JP, Tondo C (2016) Cryoballoon or radiofrequency ablation for paroxysmal atrial fibrillation. New England $\mathrm{J}$ Med 374(23):2235-2245. doi:10.1056/NEJMoa1602014

50. Nedios MdS, Sommer MdP, Bollmann DA, Hindricks G (2016) Advanced mapping systems to guide atrial fibrillation ablation: electrical information that matters. J Atrial Fibrillation 8(6):1337. doi:10.4022/jafib. 1337

51. Rillig A, Lin T, Schmidt B, Feige B, Heeger C, Wegner J, Wissner E, Metzner A, Arya A, Mathew S, Wohlmuth P, Ouyang F, Kuck KH, Tilz RR (2016) Experience matters: long-term results of pulmonary vein isolation using a robotic navigation system for the treatment of paroxysmal atrial fibrillation. Clin Res Cardiol Off J German Card Soc 105(2):106-116. doi:10.1007/ s00392-015-0892-6
52. Syed MFF, Oral MdH (2015) Electrophysiological perspectives on hybrid ablation of atrial fibrillation. J Atrial Fibrillation 8(4):1290. doi:10.4022/jafib.1290

53. Witkowski M, Bissinger A, Grycewicz T, Lubinski A (2016) Asymptomatic atrial fibrillation in patients with atrial fibrillation and implanted pacemaker. Int J Cardiol. doi:10.1016/j.ijcard. 2016.10.097

54. Erath JW, Vamos M, Sirat AS, Hohnloser SH (2017) The wearable cardioverter-defibrillator in a real-world clinical setting: experience in 102 consecutive patients. Clin Res Cardiol Off J German Card Soc 106(4):300-306. doi:10.1007/s00392-0161054-1

55. Fanola CL, Giugliano RP, Ruff CT, Trevisan M, Nordio F, Mercuri MF, Antman EM, Braunwald E (2017) A novel risk prediction score in atrial fibrillation for a net clinical outcome from the ENGAGE AF-TIMI 48 randomized clinical trial. Eur Heart J. doi:10.1093/eurheartj/ehw565

56. Jaakkola S, Lip GY, Biancari F, Nuotio I, Hartikainen JE, Ylitalo A, Airaksinen KE (2017) Predicting Unsuccessful Electrical Cardioversion for Acute Atrial Fibrillation (from the AF-CVS Score). Am J Cardiol 119(5):749-752. doi:10.1016/j.amjcard. 2016.11.026

57. Chao TF, Tsao HM, Lin YJ, Tsai CF, Lin WS, Chang SL, Lo LW, Hu YF, Tuan TC, Suenari K, Li CH, Hartono B, Chang HY, Ambrose K, Wu TJ, Chen SA (2012) Clinical outcome of catheter ablation in patients with nonparoxysmal atrial fibrillation: results of 3-year follow-up. Circ Arrhythm Electrophysiol 5(3):514-520. doi:10.1161/CIRCEP.111.968032

58. Miyazaki S, Taniguchi H, Komatsu Y, Uchiyama T, Kusa S, Nakamura H, Hachiya H, Isobe M, Hirao K, Iesaka Y (2013) Sequential biatrial linear defragmentation approach for persistent atrial fibrillation. Heart Rhythm Off J Heart Rhythm Soc 10(3):338-346. doi:10.1016/j.hrthm.2012.11.025

59. Liu J, Kaufmann J, Kriatselis C, Fleck E, Gerds-Li J (2015) Outcome of cryoballoon ablation for atrial fibrillation. Mediumterm follow-up from a single center. Herz 40 Suppl 2:125-129. doi:10.1007/s00059-014-4152-8

60. Miao CL, Yin XD, Dong JZ, Liu XP, Yu RH, Long DY, Tang $\mathrm{RB}$, Sang CH, Ma CS (2012) Catheter ablation of persistent atrial fibrillation with and without a history of paroxysmal atrial fibrillation. Chin Med J 125(6):1175-1178

61. Chang HY, Lo LW, Lin YJ, Chang SL, Hu YF, Li CH, Chao TF, Chung FP, Ha TL, Singhal R, Chong E, Yin WH, Tsao HM, Hsieh MH, Chen SA (2013) Long-term outcome of catheter ablation in patients with atrial fibrillation originating from nonpulmonary vein ectopy. J Cardiovasc Electrophysiol 24(3):250-258. doi:10.1111/jce.12036

62. Chao TF, Hung CL, Tsao HM, Lin YJ, Yun CH, Lai YH, Chang SL, Lo LW, Hu YF, Tuan TC, Chang HY, Kuo JY, Yeh HI, Wu TJ, Hsieh MH, Yu WC, Chen SA (2013) Epicardial adipose tissue thickness and ablation outcome of atrial fibrillation. PLoS One 8(9):e74926. doi:10.1371/journal.pone.0074926

63. Kim TH, Park J, Park JK, Uhm JS, Joung B, Lee MH, Pak HN (2014) Pericardial fat volume is associated with clinical recurrence after catheter ablation for persistent atrial fibrillation, but not paroxysmal atrial fibrillation: an analysis of over 600-patients. Int J Cardiol 176(3):841-846. doi:10.1016/j.ijcard.2014. 08.008

64. Evranos B, Aytemir K, Oto A, Okutucu S, Karakulak U, Sahiner L, Kaya B, Kabakci G (2013) Predictors of atrial fibrillation recurrence after atrial fibrillation ablation with cryoballoon. Cardiol J 20(3):294-303. doi:10.5603/CJ.2013.0075

65. Shim J, Joung B, Park JH, Uhm JS, Lee MH, Pak HN (2013) Long duration of radiofrequency energy delivery is an independent predictor of clinical recurrence after catheter ablation of 
atrial fibrillation: over 500 cases experience. Int J Cardiol 167(6):2667-2672. doi:10.1016/j.ijcard.2012.06.120

66. Naruse $Y$, Tada H, Satoh M, Yanagihara M, Tsuneoka H, Hirata Y, Ito Y, Kuroki K, Machino T, Yamasaki H, Igarashi M, Sekiguchi Y, Sato A, Aonuma K (2013) Concomitant obstructive sleep apnea increases the recurrence of atrial fibrillation following radiofrequency catheter ablation of atrial fibrillation: clinical impact of continuous positive airway pressure therapy. Heart Rhythm Off J Heart Rhythm Soc 10(3):331-337. doi:10.1016/j. hrthm.2012.11.015

67. Wu N, Xu B, Xiang Y, Wu L, Zhang Y, Ma X, Tong S, Shu M, Song Z, Li Y, Zhong L (2013) Association of inflammatory factors with occurrence and recurrence of atrial fibrillation: a meta-analysis. Int J Cardiol 169(1):62-72. doi:10.1016/j.ijcard. 2013.08.078

68. Zhang XD, Tan HW, Gu J, Jiang WF, Zhao L, Wang YL, Liu YG, Zhou L, Gu JN, Liu X (2013) Efficacy and safety of catheter ablation for long-standing persistent atrial fibrillation in women. Pacing Clin Electrophysiol PACE 36(10):1236-1244. doi:10. 1111/pace. 12212

69. Zhao L, Jiang W, Zhou L, Gu J, Wang Y, Liu Y, Zhang X, Wu S, Liu X (2013) Why atrial fibrillation recurs in patients who obtained current ablation endpoints with longstanding persistent atrial fibrillation. J Interv Card Electrophysiol Int J Arrhythm Pacing 37(3):283-290. doi:10.1007/s10840-013-9808-4

70. Canpolat U, Aytemir K, Yorgun H, Sahiner L, Kaya EB, Cay S, Topaloglu S, Aras D, Oto A (2014) Usefulness of serum uric acid level to predict atrial fibrillation recurrence after cryoballoonbased catheter ablation. Eur Eur Pacing Arrhythm Card Electrophysiol J Working Groups Card Pacing Arrhythm Card Cell Electrophysiol Eur Soc Cardiol 16(12):1731-1737. doi:10.1093/ europace/euu 198

71. Fujino T, Takahashi A, Kuwahara T, Takahashi Y, Okubo K, Takigawa M, Ikeda T (2014) Assessment of clinical factors associated with a successful catheter ablation outcome in younger patients with atrial fibrillation. J Cardiol 63(6):438-443. doi:10. 1016/j.jjcc.2013.10.010

72. Park J, Kim TH, Lee JS, Park JK, Uhm JS, Joung B, Lee MH, Pak HN (2014) Prolonged PR interval predicts clinical recurrence of atrial fibrillation after catheter ablation. J Am Heart Assoc 3(5):e001277. doi:10.1161/JAHA.114.001277

73. Takigawa M, Takahashi A, Kuwahara T, Okubo K, Takahashi Y, Watari Y, Takagi K, Fujino T, Kimura S, Hikita H, Tomita M, Hirao K, Isobe M (2014) Long-term follow-up after catheter ablation of paroxysmal atrial fibrillation: the incidence of recurrence and progression of atrial fibrillation. Circ Arrhythm Electrophysiol 7(2):267-273. doi:10.1161/CIRCEP.113.000471

74. Wu JT, Dong JZ, Sang CH, Tang RB, Ma CS (2014) Prolonged $\mathrm{PR}$ interval and risk of recurrence of atrial fibrillation after catheter ablation. Int Heart J 55(2):126-130

75. Canpolat U, Oto A, Hazirolan T, Sunman H, Yorgun H, Sahiner L, Kaya EB, Aytemir K (2015) A prospective DE-MRI study evaluating the role of TGF-beta1 in left atrial fibrosis and implications for outcomes of cryoballoon-based catheter ablation: new insights into primary fibrotic atriocardiomyopathy. J Cardiovasc Electrophysiol 26(3):251-259. doi:10.1111/jce.12578

76. Neumann T, Wojcik M, Berkowitsch A, Erkapic D, Zaltsberg S, Greiss H, Pajitnev D, Lehinant S, Schmitt J, Hamm CW, Pitschner HF, Kuniss M (2013) Cryoballoon ablation of paroxysmal atrial fibrillation: 5-year outcome after single procedure and predictors of success. Eur Eur Pacing Arrhythm Card Electrophysiol J Working Groups Card Pacing Arrhythm Card Cell Electrophysiol Eur Soc Cardiol 15(8):1143-1149. doi:10.1093/ europace/eut021

77. Gu J, Liu X, Tan H, Zhou L, Jiang W, Wang Y, Liu Y (2013) Impact of chronic obstructive pulmonary disease on procedural outcomes and quality of life in patients with atrial fibrillation undergoing catheter ablation. J Cardiovasc Electrophysiol 24(2):148-154. doi:10.1111/j.1540-8167.2012.02448.x 